\title{
Semen Culture: A Comparative Analysis between Solid Media and Liquid Media Supplementation
}

\author{
Alo Moses N. ${ }^{1}$, Ugah Uchenna I. ${ }^{2}$ and Elom Michael O. ${ }^{2}$ \\ ${ }^{1}$ Department of Biological Science, Federal University Ndufu-Alike Ikwo, Ebonyi State, Nigeria \\ ${ }^{2}$ Department of Medical Laboratory Science, Ebonyi State University, Abakaliki, Ebonyi State, Nigeria.
}

\begin{abstract}
Introduction: Semen culture is a salient diagnostic tool employed in the diagnosis of infection as a tentative cause of infertility. It is also used in the diagnosis of bacterial prostatitis or infection of any of the accessory glands. Semen culture is especially useful when semen is being assayed for use in in vitro fertilization or intrauterine insemination. Studies have shown that male genitourinary tract infections account for up to $15 \%$ of cases of male infertility. Materials and methods: one hundred and twenty three (123) semen samples were collected from patients attending the fertility and urology clinics of Eku Baptist Hospital. Samples were produced by masturbation in the laboratory after 3 days abstinence period. $0.1 \mathrm{ml}$ of the sample was inoculated onto broth media while $0.1 \mathrm{ml}$ was also inoculated on solid media plates. After 24 hours incubation at $37^{\circ} \mathrm{C}$, $0.1 \mathrm{ml}$ of the sample from the broth media was subcultured onto solid media plates. The media plates were read and the bacteria isolates characterized using standard methods. The isolates obtained when only solid media was used were compared with the isolates obtained when broth media was used to supplement solid media.

Result: When liquid media was used to supplement solid media in the microbiological culture of the semen sample, a total of 67 bacterial isolates were recovered whereas when only solid media was used, only 16 bacteria isolates were recovered from culture. Conclusion: the use of broth media to supplement solid media is advocated to increase the sensitivity of semen culture.
\end{abstract}

Keywords: semen culture, supplementation, broth media, Alo,Ugah,

\section{Introduction}

Semen has been described as a mixture of spermatozoa and fluids. During ejaculation, the spermatozoa which is produced from a concentrated suspension that had been stored in the paired epididymis is mixed with and diluted by fluid secretions from the accessory sex organs like the bulbourethral, urethral and prostate glands. ${ }^{[1]}$ Each of the glands and organs that contribute to semen sample are considered sterile areas separately. However, although sterility of the internal urethra is primarily maintained by the normal flow of urine, the distal urethra is not considered a sterile area hence culturing of semen samples usually yields growth of organisms, many of which are considered to be normal flora of the genitourinary tract. ${ }^{[2]}$

Semen culture is a salient diagnostic tool employed in the diagnosis of infection as a tentative cause of infertility. It is also used in the diagnosis of bacterial prostatitis or infection of any of the accessory glands. Semen culture is especially useful when semen is being assayed for use in in vitro fertilization or intrauterine insemination.

Studies have shown that male genitourinary tract infections account for up to $15 \%$ of cases of male infertility. ${ }^{[3]}$ Also, spermatogenic process and sperm cell function can be compromised by acute and chronic infections and consequent inflammation in the male reproductive systems. ${ }^{[4]}$ Semen contamination has been shown to generally originate from the urinary tract of patients or can be transmitted by the partner though sexual intercourse and the presence of bacteria in semen may compromise sperm quality. ${ }^{[5]}$

One of the post testicular causes of male infertility is infection, especially prostatitis. ${ }^{[6]}$ Prostatitis is a painful condition that mostly affects young and middle-aged men. It is usually difficult to diagnose because the symptoms are not the same for every patient and many symptoms such as painful or burning urination and incomplete emptying of the bladder could be signs of another disease. There are four types of prostatitis namely, acute and chronic bacterial prostatitis, assymptomatic inflammatory prostatitis and chronic prostatitis/chronic pelvic pain syndrome. ${ }^{[6]}$

Semen culture is therefore essential in the diagnosis of prostatitis, it has been found to have a sensitivity of $100 \%$ when used in the diagnosis of prostatitis. ${ }^{[7]}$

The purpose of this study was to examine the effect or possible advantage of supplementing solid media with liquid media over using only solid media as regards increasing the potential of isolating more organisms from semen than if only solid media is used. It is also to determine the frequency of bacteria that is present in seminal fluid. 


\section{Ethical Consideration}

\section{Materials And Methods}

Ethical clearance was sought for and obtained from the ethical committee of Eku Baptist Hospital, Eku, Delta state. Informed consent was also obtained from all the participants.

\section{Study Population}

The study was conducted among 123 adult male patients attending the fertility and urology clinic of Eku Baptist Hospital.

\section{Specimen Collection}

One hundred and twenty three (123) semen samples were collected from patients attending the fertility and urology clinics of Eku Baptist Hospital. The patients were first instructed to abstain from ejaculation for three days before returning to the laboratory for sample collection.

They were then issued with written as well as given oral instructions which among other things emphasized that they pass urine and wash hands and penis with soap , rinse away the soap before sample collection.$^{[1]}$ All the samples were collected by masturbation in the laboratory, they ejaculated into sterile widemouth universal containers.

\section{Sample Analysis}

Semen samples were allowed on the bench for 30minutes after ejaculation to liquefy before the samples were processed. The samples were inoculated on the media before semen analyses were performed.

$0.1 \mathrm{ml}$ of each of the specimen was aseptically inoculated into bijou bottles containing $20 \mathrm{ml}$ of Brain-Heart infusion broth (Oxoid Limited, Wade road, Basingstoke, Hampshire, UK) and Tetrathionate medium (SigmaAldrich Corp. St. Louis MO, USA). Also, $0.1 \mathrm{ml}$ of the specimen was inoculated on three solid media plates which are used for routine laboratory cultures, they include Chocolate agar, Blood agar and MacConkey agar (Lab M Limited, Topley house, 52 Wesh lane, Lancashire,UK). All the media were prepared according to manufacturer's instructions.

The Chocolate agar and Tetrathionate broth were incubated in anaerobic jar at $37^{\circ} \mathrm{C}$ while the other media were incubated in aerobic environment at $37^{\circ} \mathrm{C}$ for 24 hours. Subsequently, $0.1 \mathrm{ml}$ of the specimen was collected from the broth media and subcultured onto solid media plates and incubated at $37^{\circ} \mathrm{C}$ for 24hours.

The cultured plates were examined and the bacterial isolates were identified and characterized using standard methods.

After inoculation onto media plates semen analysis was performed on each of the samples using standard methods ${ }^{1}$. Aseptic techniques were strictly adhered to when processing each of the specimen and all standard operating procedures were judicially followed.

Isolates from only the solid media plates were recorded and compared with isolates obtained when the broth media were used to supplement the solid media plates.

\section{Data Analysis}

Data analysis was done using Fisher's exact test to compare the relationship between the bacteria isolated from solid media and isolates from broth media supplementation of solid media. P value of 0.05 was considered significant at 95\% confidence interval. Data analysis was done with the aid of Statistical Programme for Social Sciences (SPSS) version 17.0.

\section{Result}

Out of the 123 semen specimens cultured, 61 yielded bacterial isolates when both solid media and broth media supplementation of solid media was used, while 62 samples did not yield any bacterial growth.

Among the 61 specimen that yielded bacterial growth, 6 samples $(4.88 \%)$ yielded more than one bacterium isolate.

In all, a total of 67 bacterial isolates were recovered from the culture of the semen samples. The isolates were characterized using standard methods and identified as follows: Staphylococcus aureus, Escherichia coli, Klebsiella pneumonia, Proteus vulgaris, Pseudomonas aeruginosa, Enterobacter feacalis, Citrobacter freundii, Proteus mirabilis, coagulase negative Staphylococci, $\beta$-haemolytic Streptococci, $\alpha$-haemolytic Streptococci, Peptostreptococcus spp, Enterococcus spp, and Klebsiella spp. The frequency of these isolates are presented in table I.

When liquid media was used to supplement solid media in the microbiological culture of the semen sample, a total of 67 bacterial isolates were recovered. Whereas when only solid media was used, only 16 bacteria isolates were recovered from culture. The bacteria and their frequency of isolation when solid media was used alone and when liquid media was used to supplement solid media is presented in table II below. 
Semen Culture: A Comparative Analysis Between Solid Media And Liquid Media Supplementation

It was observed that when broth media was used to supplement solid media, more bacteria were isolated from the semen samples. Organisms belonging to the genus Streptococcus were more often isolated with broth media supplementation than with solid media alone.

The difference in bacteria isolates from solid media alone and when there is broth media supplementation was non-significant $(\mathrm{P}>0.05)$ when subjected to statistical analysis.

TABLE I SHOWING THE BACTERIA ISOLATED FROM SEMEN AND THEIR FREQUENCY

\begin{tabular}{|l|l|l|}
\hline ORGANISM & FREQUENCY & PERCENTAGE \\
\hline Staphylococcus aureus & 14 & $21 \%$ \\
\hline Escherichia coli & 14 & $21 \%$ \\
\hline Klebsiella pneumonia & 5 & $7.5 \%$ \\
\hline Proteus vulgaris & 5 & $7.5 \%$ \\
\hline Pseudomonas aeruginosa & 4 & $6 \%$ \\
\hline Enterobacter feacalis & 4 & $6 \%$ \\
\hline Citrobacter freundii & 4 & $6 \%$ \\
\hline Proteus mirabilis & 3 & $4.5 \%$ \\
\hline Coagulase negative Staphylococci & 3 & $4.5 \%$ \\
\hline$\beta$ - haemolytic Streptococci & 3 & $4.5 \%$ \\
\hline A haemolytic Streptococci & 3 & $4.5 \%$ \\
\hline Peptostreptococcus spp & 2 & $3 \%$ \\
\hline Enterococcus spp & 2 & $3 \%$ \\
\hline Klebsiella spp & 1 & $1.5 \%$ \\
\hline TOTAL & 67 & $100 \%$ \\
\hline
\end{tabular}

TABLE II SHOWING THE PREVALENCE OF THE BACTERIA ISOLATES WITH SOLID MEDIA ALONE AND WITH BROTH MEDIA SUPPLEMENTATION OF SOLID MEDIA

\begin{tabular}{|l|l|l|l|}
\hline ISOLATES & SOLID MEDIA & BROTH MEDIA + SOLID MEDIA & TOTAL \\
\hline Staphylococcus aureus & $7(33.3 \%)$ & $14(66.7 \%)$ & $21(100 \%)$ \\
\hline Escherichia coli & $4(22.2 \%)$ & $14(77.8 \%)$ & $18(100 \%)$ \\
\hline Klebsiella pneumonia & $2(28.6 \%)$ & $5(71.4 \%)$ & $18(100 \%)$ \\
\hline Proteus vulgaris & $0(0 \%)$ & $5(100 \%)$ & $7(100 \%)$ \\
\hline Pseudomonas aeruginosa & $1(20 \%)$ & $4(80 \%)$ & $5(100 \%)$ \\
\hline Enterobacter feacalis & $0(0 \%)$ & $4(100 \%)$ & $4(100 \%)$ \\
\hline Citrobacter freundii & $0(0 \%)$ & $4(100 \%)$ & $4(100 \%)$ \\
\hline Proteus mirabilis & $1(25 \%)$ & $3(75 \%)$ & $4(100 \%)$ \\
\hline Coagulase negative Staphylococci & $0(0 \%)$ & $3(100 \%)$ & $3(100 \%)$ \\
\hline$\beta$ - haemolytic Streptococci & $0(0 \%)$ & $3(100 \%)$ & $3(100 \%)$ \\
\hline$\alpha$ - haemolytic Streptococci & $0(0 \%)$ & $3(100 \%)$ & $3(100 \%)$ \\
\hline Peptostreptococcus & $0(0 \%)$ & $2(100 \%)$ & $2(100 \%)$ \\
\hline Enterococcus spp & $0(0 \%)$ & $2(100 \%)$ & $2(100 \%)$ \\
\hline Klebsiella spp & $1(50 \%)$ & $1(100 \%)$ & $2(100 \%)$ \\
\hline TOTAL & $16(19.3 \%)$ & $67(80.7 \%)$ & $83(100 \%)$ \\
\hline
\end{tabular}




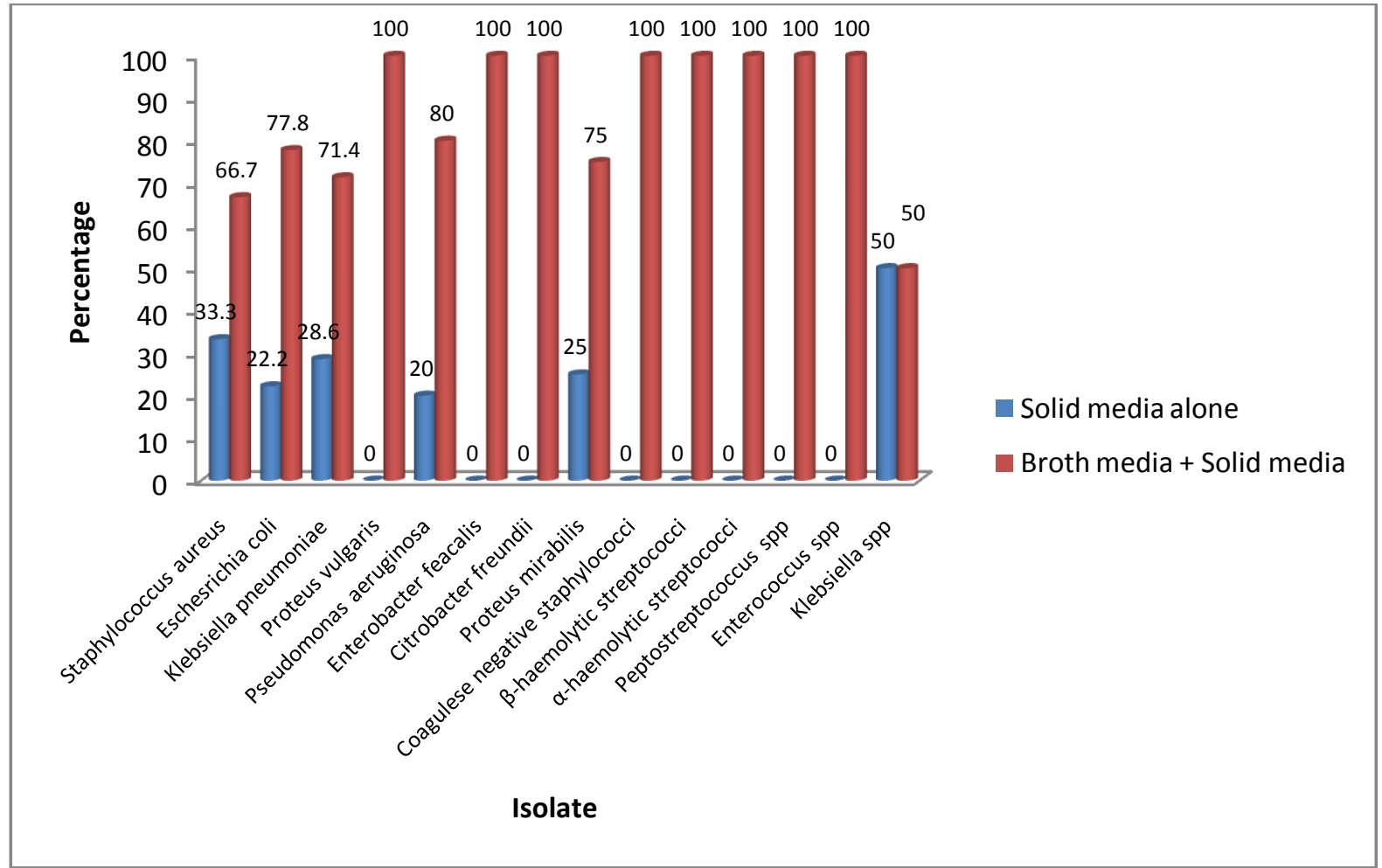

Figure 1: BAR CHART SHOWING THE PERCENTAGES OF ISOLATES IN SOLID MEDIA AND IN COMBINED LIQUID AND SOLID MEDIA

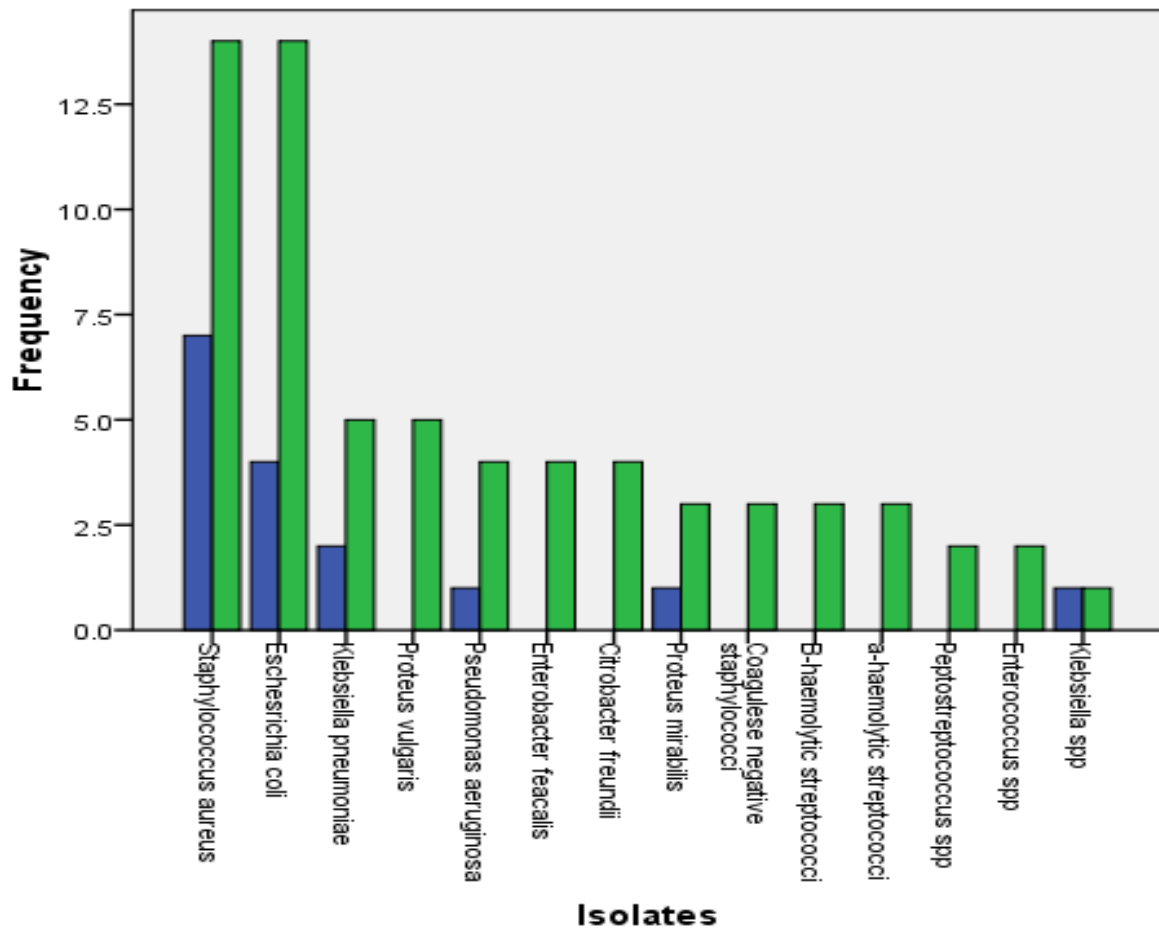

Solid media

$\square$ Solid media alone

Figure 2: BAR CHART SHOWING THE FREQUENCY OF ISOLATES IN SOLID MEDIA AND BROTH MEDIA SUPPLEMENTATION OF SOLID MEDIA 


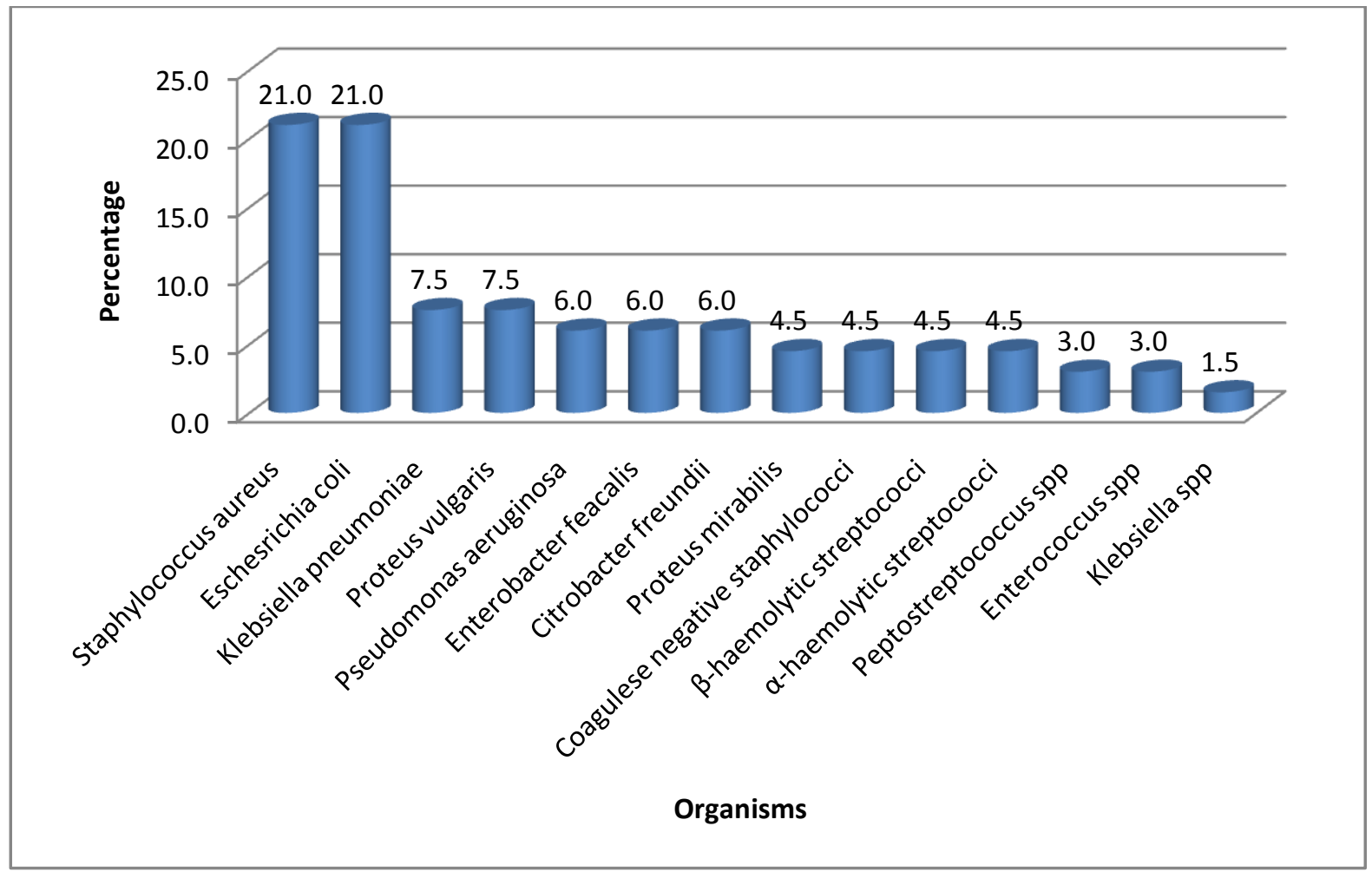

Figure 3: BAR CHART SHOWING THE PREVALENCE OF BACTERIA ISOLATES FROM SEMEN CULTURE

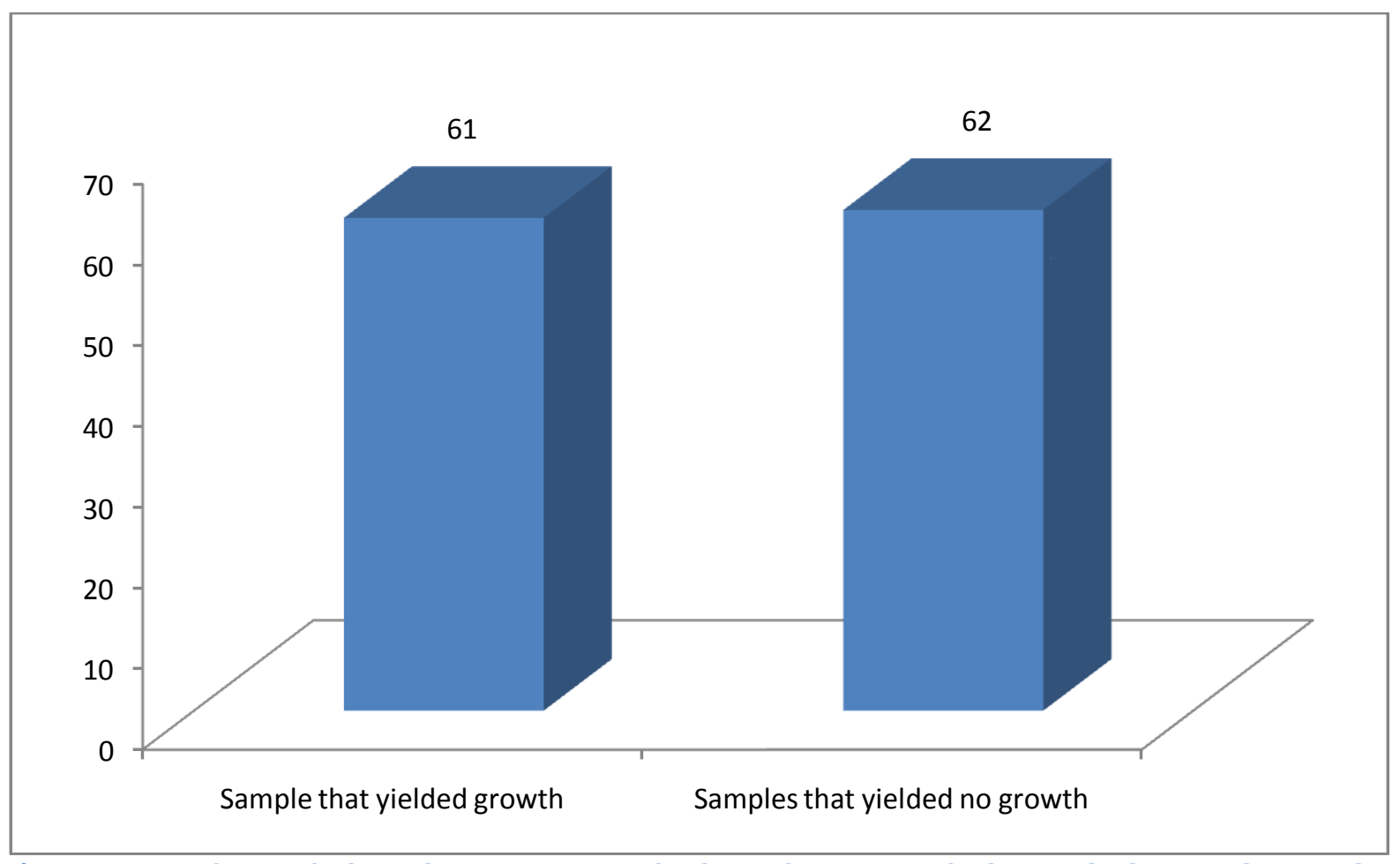

Figure 4: BAR CHART SHOWING THE PREVALENCE OF BACTERIA INFECTION AMONG THE POPULATION STUDIED

\section{Discussion}

Some studies have demonstrated that bacteria directly affect sperm quality. For instance, E.coli has been found to decrease sperm motility by binding to mannose residues on the surface of spermatozoa and therefore causing agglutination. ${ }^{[8]}$ The presence of some bacteria like S.aureus, E.coli and Ureaplasma in semen 
have also been shown to have potential adverse effects on in vitro fertilization pregnancy rates and hence semen quality. ${ }^{[2]}$

In our study, of the 123 semen samples inoculated, only 16 yielded bacterial growth when only solid media was used. However, when broth media was used to supplement the solid media 67 bacteria isolates were recovered. This is comparable to the report of another study which found that 50 isolates were recovered when only solid media was used, whereas when the solid media was enriched with broth media a total of 89 bacteria isolates were recovered. ${ }^{[9]}$

Among the bacteria isolated from the semen samples, Staphylococcus aureus and Escherichia coli were the highest isolates $(21 \%)$ when broth media was used to supplement solid media, while when only solid media was used, S. aureus was the highest bacteria isolate (43.8\%) followed by E. coli $(25.0 \%)$. This is also comparable to the study by Orji and colleagues which found $S$. aureus as the highest bacteria isolate with $37.1 \%$ but is in contrast to another study which found $E$. coli as the most isolated bacteria from semen with $70.4 \%$. $^{[7]}$ Our study was born from the observation that many patients who attend both fertility and urology clinics showed overt clinical signs of bacterial infection but when their semen samples were cultured, no bacteria was isolated. We therefore began to search for a link to explain the absence of bacteria isolates from cultures. The use of broth media to supplement the traditional solid media that are used in clinical microbiology laboratories was found to increase the sensitivity of semen culture.

The apparent increase in the frequency of bacteria isolated when broth media supplementation is employed may be attributed to the constituents of semen. It is known that semen contains minerals like zinc, citric acid, and acid phosphatase which may have antibacterial activities and as such inhibit the growth of bacteria on solid media plates but when the sample is first inoculated in broth media, the sperm cells die off over time while the minerals in the seminal plasma disintegrates. When this happens, their antibacterial effect wanes off thereby allowing the bacteria to start multiplying. This explanation is however subject to further study.

This study underscores the importance of broth media supplementation of solid media to increase the sensitivity of semen culture. The economic cost of adding broth media and the additional time that must be added before results can be issued were taken into consideration. However, when weighed with the advantage that broth media supplementation will geometrically increase the potential of isolating any bacteria from the semen sample wherever present, the benefits outweighs the discomfort.

The increased rate of isolation of Enterobacter feacalis and other predominantly intestinal bacteria from semen samples may be attributed to the changes in lifestyles and sex preferences. Anal sex may result in the transmission of bacteria which are normal flora of the intestine to the penis from where it can travel through the urethra to the male accessory sex organs like the bulbourethral, urethral and prostate glands thereby causing infection.

In conclusion, the use of broth media to supplement solid media is therefore advocated to increase the sensitivity of semen culture.

\section{References}

[1]. World Health Organisation. 2010. WHO Laboratory Manual for the Examination and Processing of Human Semen. $5^{\text {th }}$ Edition. Cambridge University Press, Cambridge, UK.

[2]. Shalika S, Dugan K, Smith RD., Padilla SL. 1996. The Effect of Positive Semen Bacterial and Ureaplasma Cultures on In vitro Fertilization Success. Hum Reprod. 11(12):2789-2792.

[3]. Pellati D, Mylonakis I, Bertoloni G, Fiore C, Andrisani A, Ambrosini G, Anmanini D. 2008. Genital Tract Infections and Infertility. Eur J Obstet Gyneacol Reprod Biol. 140: 3-11 doi:10.1016/j.ejogrb.2008.03.009.

[4]. Sanocka-Maciejewsky D, Ciupinska M, Kurpisz M 2005. Bacterial Infection and Semen Quality. J Reprod immunol. 67:51-56. doi:10.1016/j.jri.2005.06.003.

[5]. Purvis K, Christiansen E. 1993. Infection in the Male Reproductive Tract. Impact, Diagnosis and Treatment in Relation to Male Infertility. Int J Androl. 16:1-13. doi:10.1111/j.1365-2605.1993.tb01146.x.

[6]. Kreiger JN, Nyberg L Jnr., Nickel JC. 1999. NIH consensus definition and classification of prostatitis. JAMA 282(3):236-327.

[7]. Budia A, Luis PJ, Broseta E, Tejadios S, Benedicto A, Queipo JA., Gobernado M, Fernando JCJ. 2006. Value of Semen Culture in the Diagnosis of Chronic Bacterial Prostatitis : A Simplified Method. Scand. J. Urol. Nephrol. 40(4):326-331

[8]. Wolff H, Panhas A, Stoltz W, Meurer M. 1993. Adherence of Escherichia coli to Sperm A Mannose Mediated Phenomenon Leading to Agglutination Of Sperm and E. coli. J. Fertil Steril. 60(1):154-158

[9]. Orji I, Ezeifeka G, Amadi ES Okafor F. 2007. Role of Enriched media in Bacterial Isolation from Semen and Effect of Microbial Infection on Semen Quality: A Study on 100 Infertile men. Pak J Med Sci. 23(6): 855-888.

[10]. Nickel JC. 1999. Textbook of Prostatitis. Taylor \& Francis. Pp27 ISBN 978-1-901865-04-2. Retrieved 21 December 2012.

[11]. Montes LRZ, Meja AAS., Munarriz CAL, Guttierrez EC. 2008. Semen and Urine Culture in the Diagnosis of Chronic Bacterial Prostatitis. International Braz J Urol. 34(1):30-40

[12]. Mehta RH, Sridhar H, Vijay Kumar BR, Anand Kumar TC. 2002. High Incidence of Oligospermia and Teratozoospermia in Human Semen Infected With the Aerobic Bacterium Streptococcus feacalis Reprod Biomed online 5(1):17-21

[13]. Qiang H, Jiang MS., Lin JY, He WM 2007. Influence of Enterococci on Human Sperm Membrane In vitro. Asian J Androl. 9:7781 . 